\title{
Front Matter: Volume 9247
}

, "Front Matter: Volume 9247," Proc. SPIE 9247, High-Performance Computing in Remote Sensing IV, 924701 (2 December 2014); doi: 10.1117/12.2177904

SPIE. Event: SPIE Remote Sensing, 2014, Amsterdam, Netherlands 


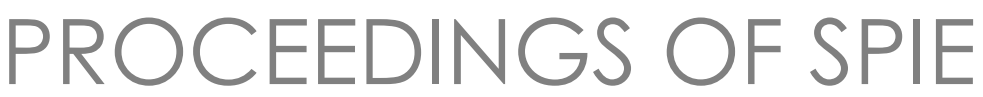

\title{
High-Performance Computing in Remote Sensing IV
}

\author{
Bormin Huang \\ Sebastian López \\ Zhensen Wu \\ Editors
}

\section{2-23 September 2014}

Amsterdam, Netherlands

Sponsored by

SPIE

Cooperating Organisations

European Association of Remote Sensing Companies (Belgium)

Remote Sensing and Photogrammetry Society (United Kingdom)

European Optical Society

CENSIS-Innovation Centre for Sensor \& Imaging Systems

EUFAR-European Facility for Airborne Research

EARSeL-European Association of Remote Sensing Laboratories

TNO

ESA

Published by

SPIE 
The papers included in this volume were part of the technical conference cited on the cover and title page. Papers were selected and subject to review by the editors and conference program committee. Some conference presentations may not be available for publication. The papers published in these proceedings reflect the work and thoughts of the authors and are published herein as submitted. The publisher is not responsible for the validity of the information or for any outcomes resulting from reliance thereon.

Please use the following format to cite material from this book:

Author(s), "Title of Paper," in High-Performance Computing in Remote Sensing IV, edited by Bormin Huang, Sebastian López, Zhensen Wu, Proceedings of SPIE Vol. 9247 (SPIE, Bellingham, WA, 2014) Article CID Number.

ISSN: 0277-786X

ISBN: 9781628413106

Published by

SPIE

P.O. Box 10, Bellingham, Washington 98227-0010 USA

Telephone +1 3606763290 (Pacific Time) · Fax +1 3606471445

SPIE.org

Copyright @ 2014, Society of Photo-Optical Instrumentation Engineers.

Copying of material in this book for internal or personal use, or for the internal or personal use of specific clients, beyond the fair use provisions granted by the U.S. Copyright Law is authorized by SPIE subject to payment of copying fees. The Transactional Reporting Service base fee for this volume is $\$ 18.00$ per article (or portion thereof), which should be paid directly to the Copyright Clearance Center (CCC), 222 Rosewood Drive, Danvers, MA 01923. Payment may also be made electronically through CCC Online at copyright.com. Other copying for republication, resale, advertising or promotion, or any form of systematic or multiple reproduction of any material in this book is prohibited except with permission in writing from the publisher. The CCC fee code is 0277-786X/14/\$18.00.

Printed in the United States of America.

Publication of record for individual papers is online in the SPIE Digital Library.

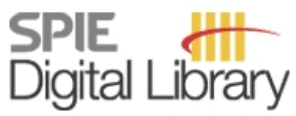

SPIEDigitalLibrary.org

Paper Numbering: Proceedings of SPIE follow an e-First publication model, with papers published first online and then in print and on CD-ROM. Papers are published as they are submitted and meet publication criteria. A unique, consistent, permanent citation identifier (CID) number is assigned to each article at the time of the first publication. Utilization of CIDs allows articles to be fully citable as soon as they are published online, and connects the same identifier to all online, print, and electronic versions of the publication. SPIE uses a six-digit CID article numbering system in which:

- The first four digits correspond to the SPIE volume number.

- The last two digits indicate publication order within the volume using a Base 36 numbering

system employing both numerals and letters. These two-number sets start with 00, 01, 02, 03, 04, 05, 06, 07, 08, 09, 0A, 0B ... 0Z, followed by 10-1Z, 20-2Z, etc.

The CID Number appears on each page of the manuscript. The complete citation is used on the first page, and an abbreviated version on subsequent pages. Numbers in the index correspond to the last two digits of the six-digit CID Number. 


\title{
Contents
}

\author{
$\checkmark \quad$ Authors \\ vii Conference Committee \\ ix Remote sensing at the NASA Kennedy Space Center and the Eastern Range: a \\ perspective from the ground up (Plenary Paper) [924 1-100]
}

\section{SESSION 1 HIGH-PERFORMANCE COMPUTING IN REMOTE SENSING I}

924702 Parallel random selection and projection for hyperspectral image analysis [9247-1]

924703 FPGA-based architecture for hyperspectral endmember extraction [9247-2]

$924704 \quad$ Intel Many Integrated Core (MIC) architecture optimization strategies for a memory-bound Weather Research and Forecasting (WRF) Goddard microphysics scheme [9247-3]

924705 FPGA implementation of the hyperspectral Lossy Compression for Exomars (LCE) algorithm (Best Student Paper Award) [9247-4]

924706 EM scattering from a 2D target above a 1D sea surface using GPU based FDTD [9247-5]

\section{SESSION 2 HIGH-PERFORMANCE COMPUTING IN REMOTE SENSING II}

924707 Hybrid DWT-DCT-Hash function based digital image watermarking for copyright protection and content authentication of DubaiSat-2 images [9247-6]

924708 Building high-performance system for processing a daily large volume of Chinese satellites imagery [9247-7]

924709 Implementation of 5-layer thermal diffusion scheme in weather research and forecasting model with Intel Many Integrated Cores [9247-8]

9247 OA A composite algorithm for variable size object tracking for high performance FPGA-based on-board vision systems [9247-9]

\section{SESSION 3 HIGH-PERFORMANCE COMPUTING IN REMOTE SENSING III}

9247 OC Initial results on computational performance of Intel Many Integrated Core (MIC) architecture: implementation of the Weather and Research Forecasting (WRF) Purdue-Lin microphysics scheme [9247-11]

9247 OD GPU efficient SAR image despeckling using mixed norms [9247-12] 
$9247 \mathrm{OE}$ Acceleration of the partitioned predictive vector quantization lossless compression method with Intel MIC [9247-14]

9247 OF Fast motion detection in coded video streams for a large-scale remote video sensor system [9247-15]

\section{SESSION 4 HIGH-PERFORMANCE COMPUTING IN REMOTE SENSING IV}

9247 OG Fast computational method of beam scattering from sea surface [9247-16]

$9247 \mathrm{OH}$ A novel highly parallel algorithm for linearly unmixing hyperspectral images [9247-17]

9247 Ol The backscattering characteristics and accelerated arithmetic for complex rough target in THz and laser bands [9247-18]

9247 0J Application of Intel Many Integrated Core (MIC) architecture to the Yonsei University planetary boundary layer scheme in Weather Research and Forecasting model [9247-19]

9247 OK Efficient parallel implementation of polarimetric synthetic aperture radar data processing [9247-20]

SESSION 5 HIGH-PERFORMANCE COMPUTING IN REMOTE SENSING V

9247 OM Optimizing zonal advection of the Advanced Research WRF (ARW) dynamics for Intel MIC [9247-22]

924700 GPU-based calculation of scattering characteristics of space target in the visible spectrum [9247-24]

9247 OP GPU-based rectification of high-resolution remote sensing stereo images [9247-25] 


\section{Authors}

Numbers in the index correspond to the last two digits of the six-digit citation identifier (CID) article numbering system used in Proceedings of SPIE. The first four digits reflect the volume number. Base 36 numbering is employed for the last two digits and indicates the order of articles within the volume. Numbers start with 00, 01, 02, 03, 04, 05, 06, 07, 08, 09, 0A, 0B...0Z, followed by 10-1Z, 20-2Z, etc.

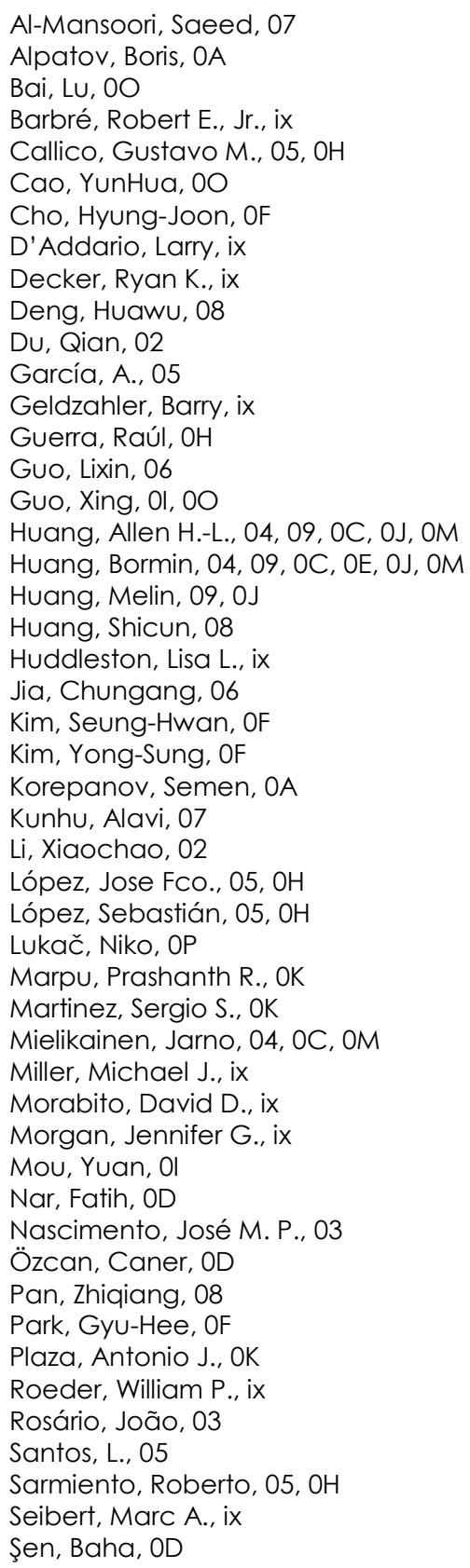


Proc. of SPIE Vol. $9247924701-6$

Downloaded From: https://www.spiedigitallibrary.org/conference-proceedings-of-spie on 26 Apr 2023 Terms of Use: https://www.spiedigitallibrary.org/terms-of-use 


\section{Conference Committee}

Symposium Chair

Charles R. Bostater Jr., Florida Institute of Technology (United States)

Symposium Co-chairs

Ulrich Michel, University of Education Heidelberg (Germany)

Bart Snijders, TNO (Netherlands)

\section{Conference Chairs}

Bormin Huang, University of Wisconsin-Madison (United States)

Sebastian López, Universidad de Las Palmas de Gran Canaria (Spain)

Zhensen Wu, Xidian University (China)

\section{Conference Program Committee}

Saeed H. Al-Mansoori, Emirates Institution for Advanced Science and Technology (United Arab Emirates)

Philip E. Ardanuy, Raytheon Intelligence \& Information Systems (United States)

Chein-I Chang, University of Maryland, Baltimore County (United States)

Yang-Lang Chang, National Taipei University of Technology (Taiwan)

David J. Crain, GeoMetWatch Corporation (United States)

Qian Du, Mississippi State University (United States)

Mitch Goldberg, National Environmental Satellite, Data, and Information Service (United States)

Carlos Gonzalez, Universidad Complutense de Madrid (Spain)

Lixin Guo, Xidian University (China)

Hunglung Allen Huang, University of Wisconsin-Madison (United States)

Tung-Ju Hsieh, National Taipei University of Technology (Taiwan)

Dieter Just, European Organisation for the Exploitation of Meteorological Satellites (Germany)

Tsengdar J. Lee, NASA Headquarters (United States)

Francesco Leporati, Università degli Studi di Pavia (Italy)

Prashanth Reddy Marpu, Masdar Institute of Science \& Technology (United Arab Emirates)

Jarno Mielikainen, University of Wisconsin-Madison (United States)

J. Montgomery, Georgetown University (United States)

Jose M. P. Nascimento, Instituto de Telecomunicações (Portugal)

Abel Paz, Universidad de Extremadura (Spain) 
Antonio J. Plaza, Universidad de Extremadura (Spain)

Jeffery J. Puschell, Raytheon Space \& Airborne Systems

(United States)

Shen-En Qian, Canadian Space Agency (Canada)

Stefan A. Robila, Montclair State University (United States)

Joan Serra-Sagrista, Universitat Autònoma de Barcelona (Spain)

Yuliya Tarabalka, INRIA Sophia Antipolis - Méditerranée (France)

Carole Thiebaut, Centre National d'Études Spatiales (France)

Tanya Vladimirova, University of Leicester (United Kingdom)

Shih-Chieh Wei, Tamkang University (Taiwan)

Jiaji Wu, Xidian University (China)

Ye Zhang, Harbin Institute of Technology (China)

\section{Session Chairs}

1 High-Performance Computing in Remote Sensing I

Bormin Huang, University of Wisconsin-Madison (United States)

2 High-Performance Computing in Remote Sensing II

Sebastian López, Universidad de Las Palmas de Gran Canaria (Spain)

3 High-Performance Computing in Remote Sensing III

Zhensen Wu, Xidian University (China)

4 High-Performance Computing in Remote Sensing IV

Qian Du, Mississippi State University (United States)

5 High-Performance Computing in Remote Sensing $\mathrm{V}$

Saeed H. Al-Mansoori, Emirates Institution for Advanced Science and Technology (United Arab Emirates) 


\title{
Remote sensing at the NASA Kennedy Space Center and the Eastern Range: a perspective from the ground up
}

\author{
Lisa L. Huddleston ${ }^{\mathrm{a} *}$, William P. Roeder ${ }^{\mathrm{b}}$, \\ David D. Morabito ${ }^{c}$, Larry D'Addario ${ }^{c}$, Jennifer G. Morgan $^{\mathrm{a}}$, \\ Robert E. Barbré, Jr. ${ }^{\text {d }}$, Ryan K. Deckere, \\ Barry Geldzahler ${ }^{\mathrm{f}}$, Marc A. Seibert ${ }^{\mathrm{a}}$, Michael J. Miller ${ }^{\mathrm{a}}$ \\ ${ }^{a}$ National Aeronautics and Space Administration, Kennedy Space Center, FL, \\ ${ }^{\mathrm{b}}$ United States Air Force, Patrick Air Force Base, FL, \\ ${ }^{c}$ National Aeronautics and Space Administration, Jet Propulsion Laboratory, California Institute of \\ Technology \\ ${ }^{\mathrm{d}}$ National Aeronautics and Space Administration, Marshall Space Flight Center, Jacobs \\ ${ }^{\mathrm{e}}$ National Aeronautics and Space Administration, Marshall Space Flight Center, AL \\ ${ }^{\mathrm{f}}$ National Aeronautics and Space Administration, Headquarters, DC
}

\begin{abstract}
This paper provides an overview of ground based operational remote sensing activities that enable a broad range of missions at the Eastern Range (ER), which includes the National Aeronautics and Space Administration (NASA) Kennedy Space Center (KSC) and U.S. Air Force Cape Canaveral Air Force Station (CCAFS).

Many types of sensors are in use by KSC and across the ER. We examine remote sensors for winds, lightning and electric fields, precipitation and storm hazards. These sensors provide data that are used in real-time to evaluate launch commit criteria during space launches, major ground processing operations in preparation for space launches, issuing weather warnings/watches/advisories to protect over 25,000 people and facilities worth over $\$ 20$ billion, and routine weather forecasts. The data from these sensors are archived to focus NASA launch vehicle design studies, to develop forecast techniques, and for incident investigation. The wind sensors include the 50-MHz and 915-MHz Doppler Radar Wind Profilers (DRWP) and the Doppler capability of the weather surveillance radars. The atmospheric electricity sensors include lightning aloft detectors, cloud-to-ground lightning detectors, and surface electric field mills. The precipitation and storm hazards sensors include weather surveillance radars.

Next, we discuss a new type of remote sensor that may lead to better tracking of near-Earth asteroids versus current capabilities. The Ka Band Objects Observation and Monitoring (KaBOOM) is a phased array of three 12 meter $(\mathrm{m})$ antennas being built as a technology demonstration for a future radar system that could be used to track deep-space objects such as asteroids. Transmissions in the Ka band allow for wider bandwidth than at lower frequencies, but the signals are also far more susceptible to de-correlation from turbulence in the troposphere, as well as attenuation due to water vapor, which is plentiful in the Central Florida atmosphere. If successful, KaBOOM will have served as the pathfinder for a larger and more capable instrument that will enable tracking $15 \mathrm{~m}$ asteroids up to 72 million kilometers $(\mathrm{km})$ away, about half the distance to the Sun and five times further than we can track today.
\end{abstract}

Finally, we explore the use of Site Test Interferometers (STI) as atmospheric sensors. The STI antennas continually observe signals emitted by geostationary satellites and produce measurements of the phase difference between the received signals. STIs are usually located near existing or candidate antenna array sites to statistically characterize atmospheric phase delay fluctuation effects for the site. An STI measures the fluctuations in the difference of atmospheric delay from an extraterrestrial source to two or more points on the Earth. There is a three-element STI located at the KaBOOM site at KSC.

*Corresponding author: lisa.1.huddleston@nasa.gov; phone 1321 861-4952; fax 1321 861-7907

Sensors, Systems, and Next-Generation Satellites XVIII, edited by Roland Meynart, 
Keywords: Remote sensing, Eastern Range (ER), Kennedy Space Center (KSC), Cape Canaveral Air Force Station (CCAFS) weather, radar, lightning sensors, Doppler Radar Wind Profilers (DRWPs), antenna arrays, atmospheric fluctuations, coherent uplink, phased arrays, adaptive optics, site test interferometers (STIs)

\section{INTRODUCTION}

Remote sensing has become a common term in atmospheric and environmental discussions. The vast majority of the references deal with data produced by space based or "satellite remote sensing" instruments. There is however a broad range of remote sensing applications that are ground based. A number of these applications are currently in use at the Eastern Range (ER, Appendix A contains an acronym list) which includes Kennedy Space Center (KSC) and Cape Canaveral Air Force Station (CCAFS) in Florida (FL) to support a broad range of National Aeronautics and Space Administration (NASA), United States Air Force (USAF) and commercial space launch missions. This paper describes the vital role that ground based remote sensing plays in launch operations, personnel safety, resource protection, and historical databases for mission planning and forecast improvement; in deep space investigations; and in research to measure the effects of turbulence in the atmosphere on space communication, navigation and radar signals.

\section{WEATHER AND LAUNCH OPERATIONS}

Comprehensive weather services to the United States of America's space program at the ER is provided by the USAF's 45th Weather Squadron (45WS) ${ }^{1}$. To provide these services, the ER and 45WS use extensive networks of ground-based instrumentation to ensure successful launch operations and to aid in vehicle design. These networks comprise the most unique and dense suite of weather sensors found in operational meteorology today. Lightning detection systems, specifically the Launch Pad Lightning Warning System (LPLWS), the Four Dimensional Lightning Surveillance System (4DLSS), and the National Lightning Detection Network (NLDN), are used to detect lightning and assess the Lightning Launch Commit Criteria (LCC). The C-Band Weather Radar assists in applications that include high precision lightning forecasting, evaluating lightning LCC, stringent convective wind prediction, severe weather warnings, hail detection, heavy rain advisories, and warning of local tropical system threats. The Doppler Radar Wind Profiler (DRWP) system provides wind profiles used to evaluate loads on both day-of-launch and during vehicle design assessments.

Weather is the leading cause for launch scrubs and delays and has a large impact on many aspects of space launch activities. These include active launch operations, ground processing operations in preparation for launch, post-launch operations, various special missions, routine $24 / 7$ weather watch and warning responsibilities for personnel safety, resource protection and mission planning. During launch countdowns, the 45WS forecasts and evaluates the Lightning LCC, Range LCC, and User LCC ${ }^{2}$. [2] The Lightning LCC are a set of complex rules used to avoid natural and rocket triggered lightning ${ }^{3,4,5}$. The Range LCC include boundary layer profiles of wind, temperature and moisture that are primarily used for predicting transport and dispersion of atmospheric constituents. This is especially important in the event of an explosion or other major malfunction where toxic chemicals are released into the atmosphere. Many atmospheric phenomena generate and/or store electrical charge that is insufficient to cause natural lightning. However, when a large rocket flies near those areas of electric charge, the long conductive exhaust plume and length of the metal rocket can amplify the associated electric fields by a factor of over 100. If the amplified electric field exceeds the breakdown voltage of the air, a rocket triggered lightning occurs. While the lightning can damage the rocket itself, or more likely the onboard electronics, the greatest concern is the lightning may damage the flight termination system. This would stop the ability of the flight controllers from being able to destroy the rocket if it goes too far off course. The User LCC are limits for various weather categories such as near surface winds so the rocket can safely clear the launch tower, temperature for mechanical integrity of the rocket, and precipitation to avoid damaging the rocket while in-flight. Requirements also exist for upper level winds to avoid over stressing the space launch vehicle as it counter-steers through the actual winds versus the planned winds to stay on the correct trajectory and achieve the desired orbit. The User LCC varies between launch vehicle programs and different configurations of vehicles in the same program ${ }^{6}$.

The 45WS is responsible for the weather safety of over 25,000 personnel and resource protection for over $\$ 20$ billion of facilities, not including the payloads and space launch vehicles. Each year, the remote sensing capabilities at KSC facilitate the issuance of over 2,500 weather warnings, watches, and advisories. These include warnings for tornadoes, large hail, strong winds, and imminent or occurring lightning; watches for convective winds, steady state winds, developing lightning, and heavy rain; and advisories for temperature. Over 5,000 ground processing operations are 
performed annually in preparation for space launches ${ }^{7}$. Major ground processing operations include vehicle rollouts to the launch pads, stacking and destacking rocket segments, transporting and mounting and demounting payloads, and large crane operations. Crane lifts can be very wind sensitive, especially when lifting fueled solid rocket boosters, multibillion dollar payloads, or multi-million dollar rocket segments. Minor operations can be as simple as performing corrosion maintenance on the launch pads. Many of these processing operations are conducted outside and must be curtailed under certain weather conditions. Some processing operations have restrictive weather limits that can result in weeks of delay ${ }^{6}$.

The hazards of lightning, both natural and triggered, are well known and include direct and indirect effects. Direct effects include heating, pitting or melt-through of conducting materials, puncturing or splintering of nonmetallic surfaces, burning holes in the skin, the welding or fusing of hinges and bearings; damage to antennas and/or lights; and, rarely, explosions due to the ignition of fuel vapors ${ }^{8}$. Indirect effects include any momentary upsets or permanent damage caused by the transient voltages and currents that are induced by direct or nearby discharges ${ }^{8}$. For most spacecraft, the penalties in added cost and weight of hardening against these hazards are too great, so the only option is avoidance ${ }^{9}$. Lightning is also a significant weather safety hazard, being the third leading source of storm deaths in the United States $^{10}$.[10] Lightning advisories are issued for 10 areas, consisting of circles with a 9.26 kilometer $(\mathrm{km}, 5$ nautical mile (NM)) or $11.11 \mathrm{~km}(6 \mathrm{NM})$ radii safety buffer centered on operationally significant sites: seven areas with considerable overlap on CCAFS/KSC, one with little overlap on KSC, one at Patrick Air Force Base (AFB), and one for a satellite processing facility at Titusville (Figure 1). A Phase-1 Lightning Watch is issued for one or more of these areas if lightning is expected with a desired lead-time of $30 \mathrm{~min}$. A Phase-II Lightning Warning is issued when lightning is imminent or occurring in one or more of these areas. One of the greatest challenges is the ability to reliably cancel these lightning advisories more quickly to allow outdoor work to resume, while still maintaining safety ${ }^{6}$. As one might expect with all the thunderstorm activity, convective wind warnings are also important, with an average of over 175 warnings each year. The convective wind warnings have unusually precise requirements and large desired lead-times ${ }^{6}$.

In addition to those items already discussed, four other aspects of launch are evaluated for weather concerns. The first launch aspect is 'LOADS', which refers to the aerodynamic loading on the rocket as it counter-steers against the upperlevel winds to stay on the desired trajectory. If the actual winds differ too much from the assessed winds, the rocket could destroy itself. The LOADS community of aeronautical engineers continually analyzes the observed winds and assesses their impact to the vehicle to prevent this from happening. There is an extensive archive of vertically complete wind profiles generated by the Marshall Space Flight Center (MSFC) Natural Environments (NE) group using the DRWP network at the ER. This archive is used to mitigate the multiple shortcomings of utilizing balloon-based measurements for space vehicle loads and trajectory assessments. Launching vehicles into space requires accurately characterizing the wind environment that the vehicle will experience through ascent. Specific effects of the ascent winds on launch vehicles depend on the characteristics of the vehicle components and the magnitude of the wind acting on those components ${ }^{11}$. Range Safety evaluates the second, third, and fourth aspects of launch: 'Toxic Dispersion', 'BLAST', and 'Debris' ${ }^{12}$. Toxic dispersion from nominal and catastrophic launches is analyzed to ensure that they will not exceed allowable toxic exposure limits for the on-base and nearby civilian populations. 'BLAST' analyzes the likelihood of windows in nearby towns being broken and causing a safety hazard if a rocket explodes ${ }^{13}$. The 'Debris' program considers if parts of the rocket from a nominal or catastrophic launch would fall outside of the allowed impact areas ${ }^{6}$. 


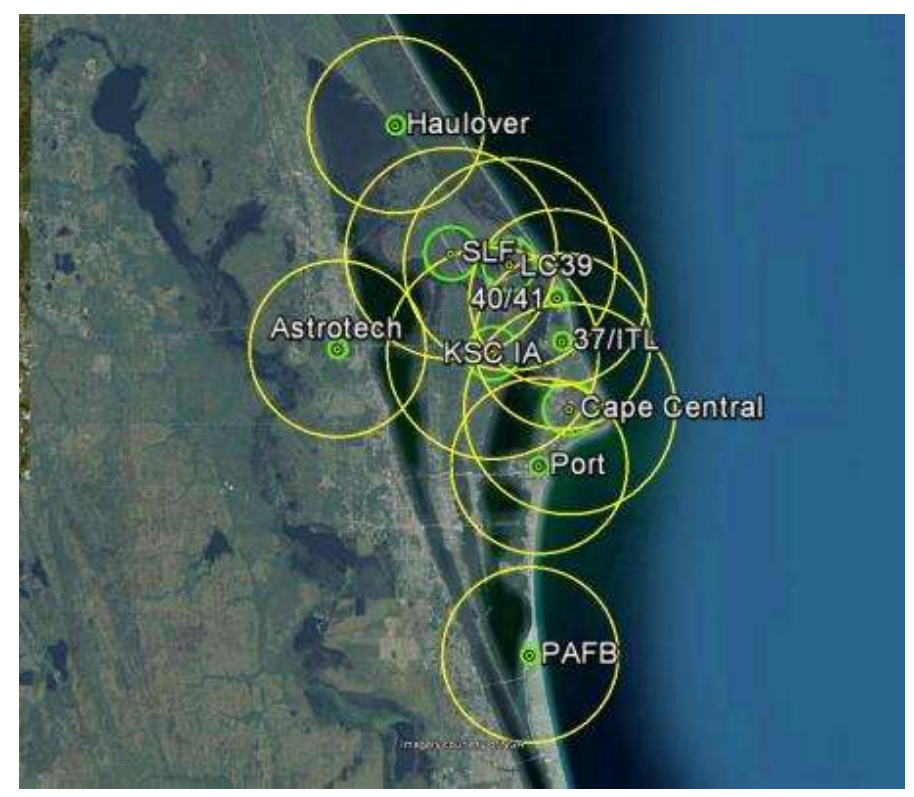

Figure 1 . The 10 lightning warning circles used by 45 WS.

\subsection{Eastern Range Weather Systems}

The ER possesses one of the world's most dense operational networks of weather instrumentation ${ }^{14}$. This instrumentation is used to minimize the impact of weather while ensuring the safe processing and launching of space vehicles. Some, but not all, of these weather instruments use remote sensing. For example, the ER uses a network of 28 weather towers that measures wind, temperature, and moisture in the first few hundred feet of the atmosphere. However, this paper will focus only on the ER weather instruments that use ground-based remote sensing. These include lightning detection systems, the DRWPs, and the weather radar. The ground-based remote sensing weather sensors and the data they provide are listed in Table 1.

Table 1. Ground-based remote sensing weather sensors at the Eastern Range

\begin{tabular}{|c|c|c|}
\hline Sensor & Data Provided & Main Operational Applications \\
\hline $\begin{array}{l}\text { Four Dimensional Lightning } \\
\text { Surveillance System } \\
\text { (4DLSS) }\end{array}$ & $\begin{array}{l}\text { - Cloud-to-Ground Lightning } \\
\text { - return strokes (not flashes) } \\
\text { - latitude, longitude } \\
\text { - date, time } \\
\text { - peak current, polarity } \\
\text { - Lightning aloft } \\
\text { - step leaders } \\
\text { - latitude, longitude, height } \\
\text { - date, time }\end{array}$ & $\begin{array}{l}\text { - Assess risk of induced current damage, } \\
\text { Lightning warnings (approaching storms), } \\
\text { Evaluate Lightning LCC } \\
\text { - Lightning warnings } \\
\text { Evaluate Lightning LCC }\end{array}$ \\
\hline $\begin{array}{l}\text { Launch Pad Lightning } \\
\text { Warning System (LPLWS) }\end{array}$ & - Surface electric field & - Evaluate Lightning LCC \\
\hline Weather Radar & $\begin{array}{l}\text { - Reflectivity } \\
\text { - Doppler velocity } \\
\text { - Spectral width } \\
\text { - Differential reflectivity }\end{array}$ & $\begin{array}{l}\text { - Lightning prediction, Lightning LCC } \\
\text { evaluation, severe weather warnings, } \\
\text { precipitation detection, general weather } \\
\text { support } \\
\text { - Severe weather warnings } \\
\text { - None } \\
\text { - Possibly lightning onset and hydrometeor } \\
\text { identification for lightning cessation, hail }\end{array}$ \\
\hline
\end{tabular}




\begin{tabular}{|c|c|c|}
\hline Sensor & Data Provided & Main Operational Applications \\
\hline & $\begin{array}{l}\text { - Phase differential } \\
\text { - Correlation coefficient }\end{array}$ & $\begin{array}{l}\text { warnings, tornado detection, etc. } \\
\text { - Possibly hydrometeor identification for } \\
\text { lightning cessation, hail, tornado, etc. } \\
\text { - Possibly hydrometeor identification for } \\
\text { lightning cessation, hail, tornado, etc. }\end{array}$ \\
\hline $\begin{array}{l}\text { 50-MHz Doppler Radar } \\
\text { Wind Profiler (50DRWP) }\end{array}$ & $\begin{array}{l}\text { - Vertical wind profiles } \\
\text { - wind speed/direction } \\
\text { vs. height (base-top) }\end{array}$ & - Evaluate LOADS \\
\hline $\begin{array}{l}\text { 915-MHz Doppler Radar } \\
\text { Wind Profiler (915DRWP) }\end{array}$ & $\begin{array}{l}\text { - Vertical wind profiles } \\
\text { - wind speed/direction } \\
\text { vs. height (base-top) }\end{array}$ & $\begin{array}{l}\text { - Evaluate toxic dispersion, BLAST, and } \\
\text { Debris }\end{array}$ \\
\hline
\end{tabular}

\subsection{Lightning Detection Systems}

The ER is well instrumented with respect to lightning detection sensors. These sensors exist not only because lightning can adversely affect the vehicle and corresponding operations, but also because central Florida is the area of highest lightning activity in the United States (U.S.) ${ }^{15}$ The ER utilizes the Launch Pad Lightning Warning System (LPLWS), the Four Dimensional Lightning Surveillance System (4DLSS), and the National Lightning Detection Network (NLDN) to detect lightning.

The LPLWS consists of a network of 31 field mills distributed in and around the launch and operations areas of CCAFS and KSC. The location of the 31 mills is shown in Figure 2 and picture of one of the field mills is shown in Figure 3 The network measures the electric field at the surface, which is used to infer electric fields aloft - a key to evaluating the danger of triggered lightning during launch operations ${ }^{14}$. In the Lightning LCC, field mills can be used to either avoid launch under hazardous conditions, or to allow safe launch that otherwise would have been falsely identified as hazardous. The one-minute average of the electric field mill network may not exceed -1 or +1 kilovolts per meter $(\mathrm{kV} / \mathrm{m})$ within $9.26 \mathrm{~km}(5 \mathrm{NM})$ of the launch pad or the lightning flash at any time within 15 minutes prior to launch. This field mill criteria becomes -1.5 or $+1.5 \mathrm{kV} / \mathrm{m}$ if there are no clouds within $18.52 \mathrm{~km}(10 \mathrm{NM})$ of the flight path except those that are transparent ${ }^{3,4,5}$.

The 4DLSS detects both cloud-to-ground return strokes and lightning aloft ${ }^{16,17}$.[16] The 4DLSS was a major upgrade to the previous Lightning Detection and Ranging (LDAR) system that detected lightning aloft and the Cloud to Ground Lightning Surveillance System (CGLSS) ${ }^{16,17}$. The cloud-to-ground lightning part of the network consists of a network of six low frequency (LF) magnetic direction-finding and time-of-arrival (IMPACT) sensors located in and around the launch and operations areas of CCAFS and KSC (Figure 4). A picture of one of these sensors is shown in Figure 5. They are deployed on relatively short baselines and operate at low gain to ensure the requirements for high location accuracy and detection efficiency of cloud-to-ground strikes are satisfied ${ }^{14}$. This part of 4DLSS provides the latitude, longitude, time, peak current, and polarity for each return stroke within a lightning flash. The lightning aloft part of 4DLSS consists of a network of nine receiver sites which detect inter-cloud, intra-cloud and cloud-to-ground lightning. Lightning aloft is geolocated using VHF time-of-arrival between multiple pairs of sensors ${ }^{14}$. The locations of the sensors is shown in Figure 6 with an example of one of the sensors is at Figure 7. The time-of-arrival differences between multiple pairs of sensors is used to locate the three dimensional (3-D) structure of the lightning. The 4DLSS is being replaced with a new system to overcome sustainment problems of the old sensors and take advantage of improvements in lightning detection technology. The new system is the Mesoscale Eastern Range Lightning Network (MERLiN).

The 45WS also has a direct link to the NLDN, which is a network of about 130 cloud-to-ground sensors across the contiguous U.S ${ }^{18}$. The NLDN is also has a relatively new low detection efficiency capability for detecting lightning aloft. This NLDN link is used as a back-up to the cloud-to-ground portion of 4DLSS, for cloud-to-ground lightning detection capability for occasional missions beyond the range of 4DLSS, and as supplemental quality control of 4DLSS cloud-toground lightning. 


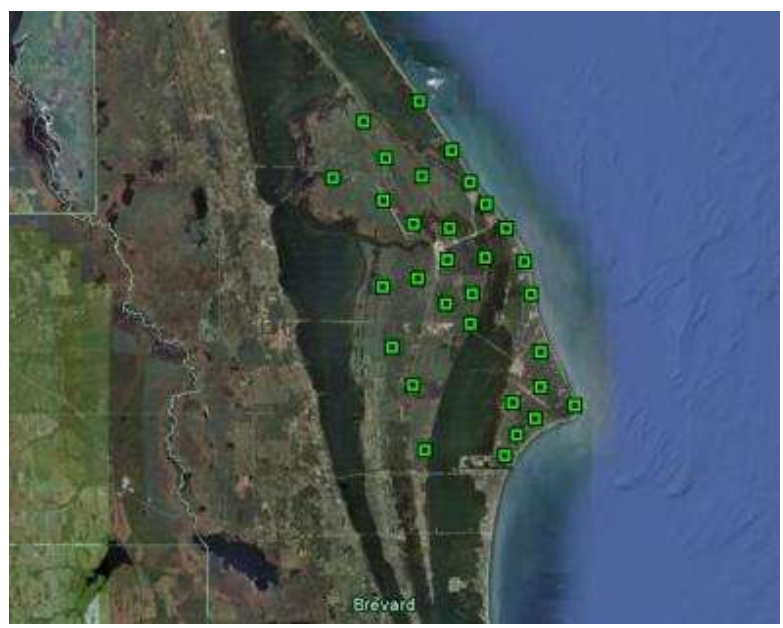

Figure 2. Field mill sensor locations.

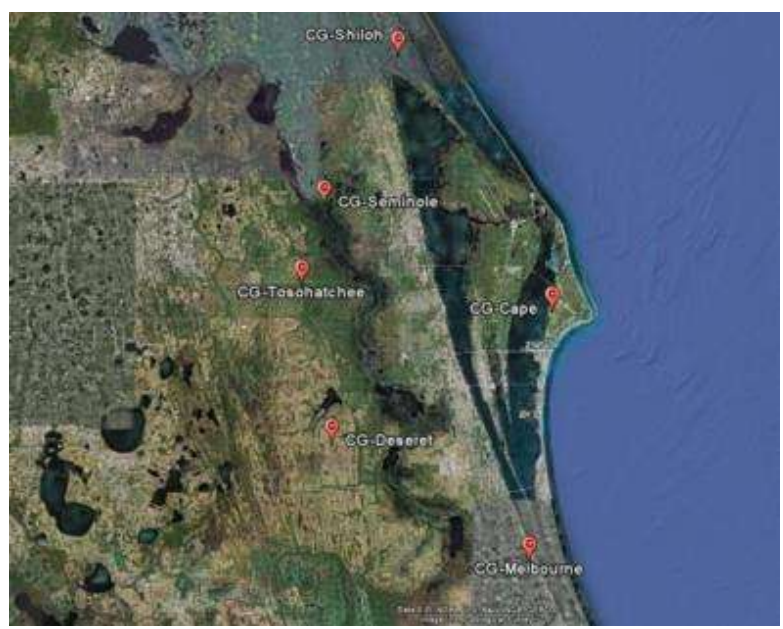

Figure 4. CGLSS sensor locations.

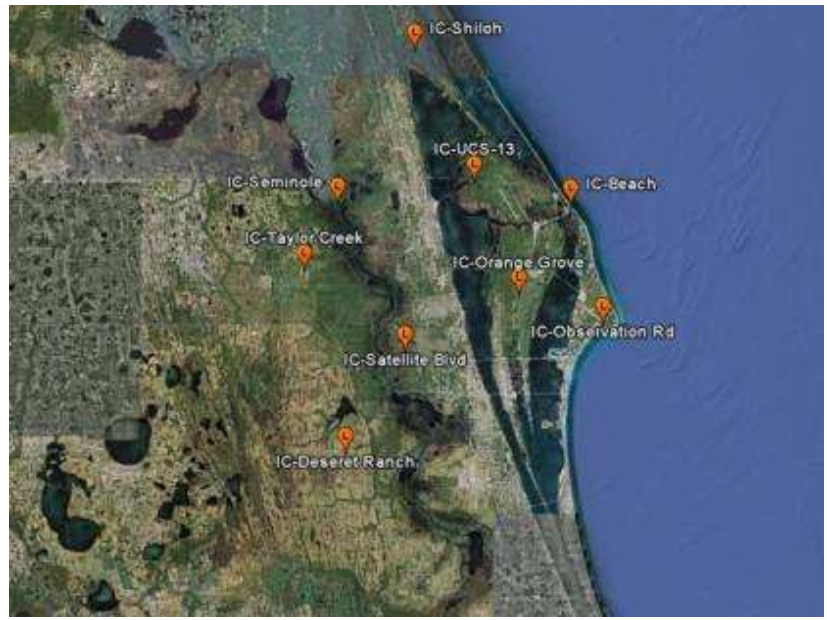

Figure 6. An LDAR-II sensor.

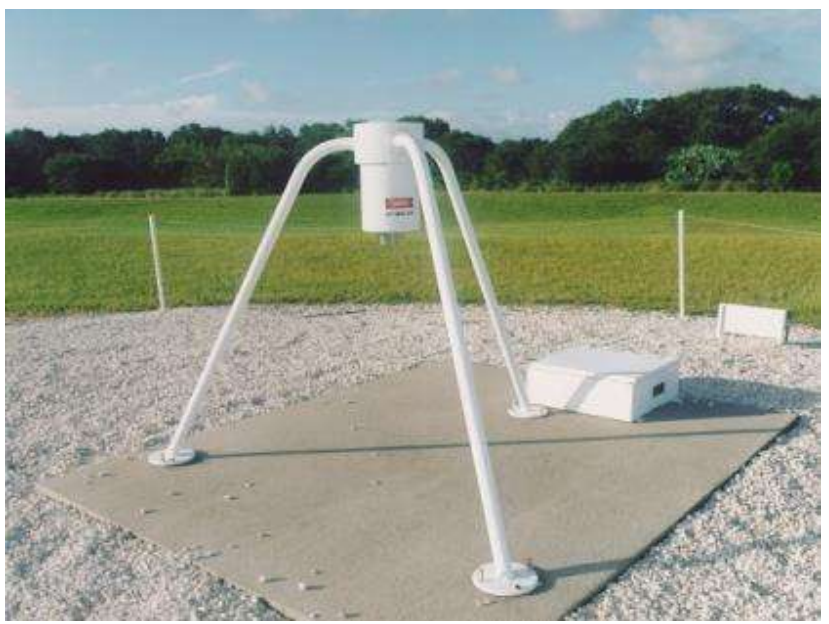

Figure 3. A field mill sensor

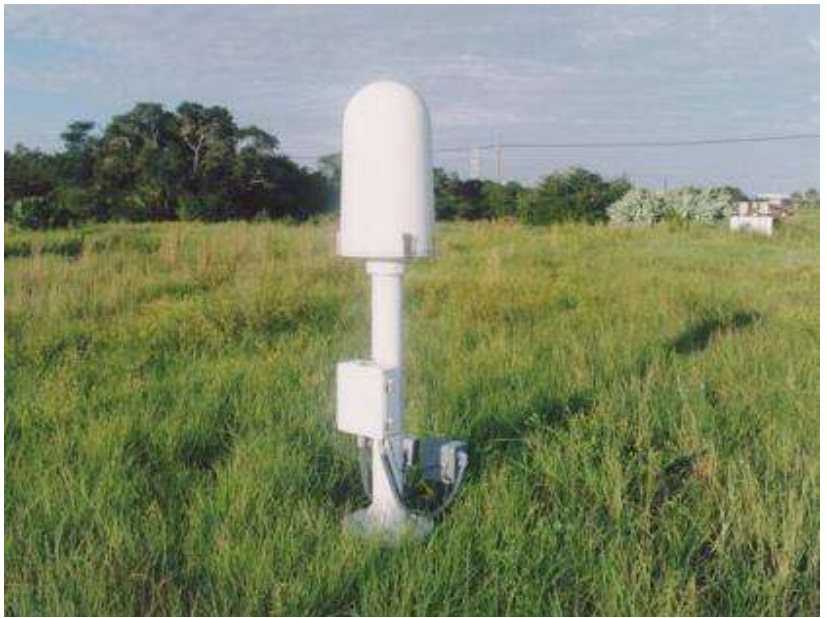

Figure 5. A CGLSS sensor.

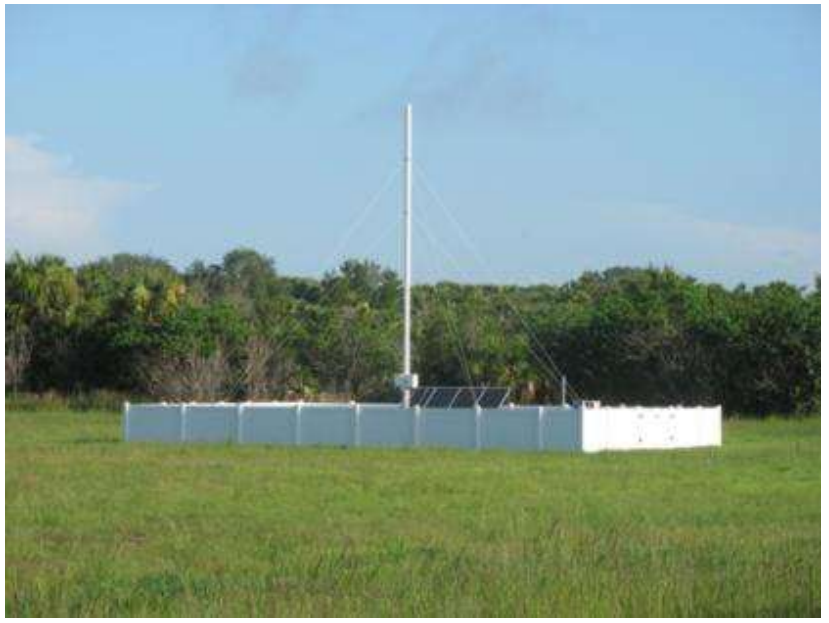

Figure 7. LDAR-II sensor locations. 


\subsection{Weather Radar}

One of the most important weather sensors is the C-band $(5 \mathrm{~cm})$ Radtec Titan Doppler Radar with $4.3 \mathrm{~m}$ diameter antenna and $250 \mathrm{~kW}$ average transmitted power (TDR 43-250) manufactured by Radtec Engineering, Inc ${ }^{19}$. The space program on the ER makes use of several atypical applications of weather radar ${ }^{20}$. These applications include high precision lightning forecasting, evaluating lightning LCC, stringent convective wind prediction, severe weather warnings, hail detection, heavy rain advisories, and warning of local tropical system threats ${ }^{20}$. The location of the $45 \mathrm{WS}$ radar and a picture of the radar are shown in Figure 8 and

Figure 9, respectively.

The TDR 43-250 radar is a dual polarization Doppler weather surveillance radar that detects reflectivity, Doppler velocity, spectral width, differential reflectivity, phase differential, and correlation coefficient. Reflectivity indicates the intensity of precipitation, and the shape and motion of thunderstorms that can imply the type and intensity of hazard they may produce. Reflectivity is especially useful in forecasting the onset of lightning in locally developing thunderstorms $^{21,22}$ and in evaluating Lightning LCC. Doppler velocity can detect storm rotation that can indicate severe weather, especially tornadoes. Differential reflectivity, phase differential, and correlation are new dual polarization capabilities that should have many new capabilities including lightning formation ${ }^{21,22}$, lightning cessation, hail detection, tornado detection ${ }^{23}$, and eventually Lightning LCC evaluation.

The 45WS also has a direct feed from the Weather Surveillance Radar - 1988 Doppler (WSR-88D radar) at Melbourne, FL. This radar is part of the Next Generation Weather Radar (NEXRAD) network shared by the Department of Defense (DoD), National Weather Service (NWS), and the Federal Aviation Administration (FAA). This radar is an S-band (10 $\mathrm{cm})$ dual polarization Doppler weather surveillance radar. This radar serves as a back-up to the Radtec radar and provides dual wavelength capability in combination with the $45 \mathrm{WS}$ radar.

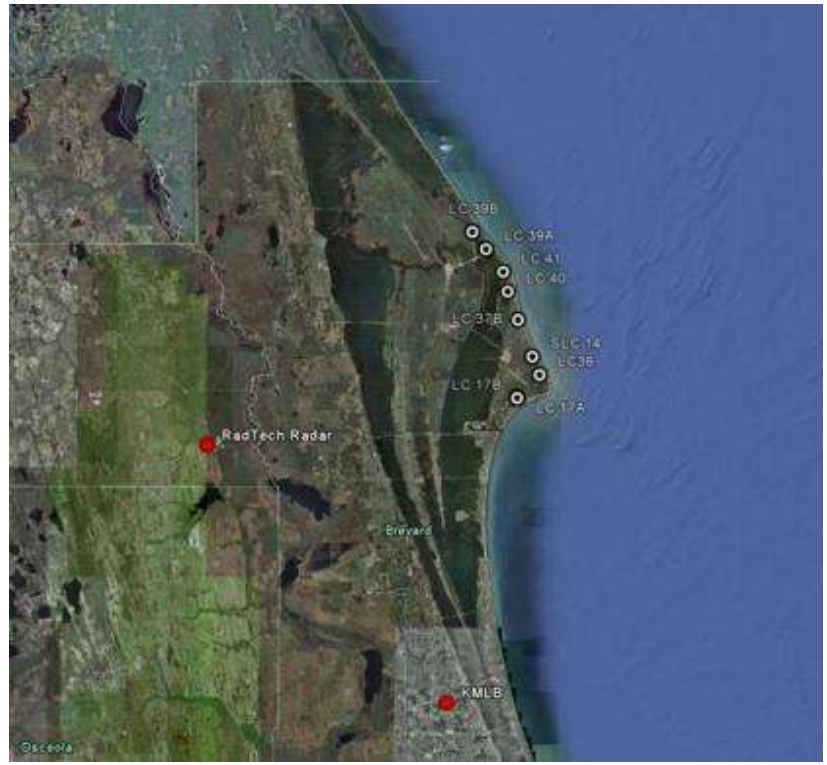

Figure 8. Locations of radars used by $45 \mathrm{WS}$.

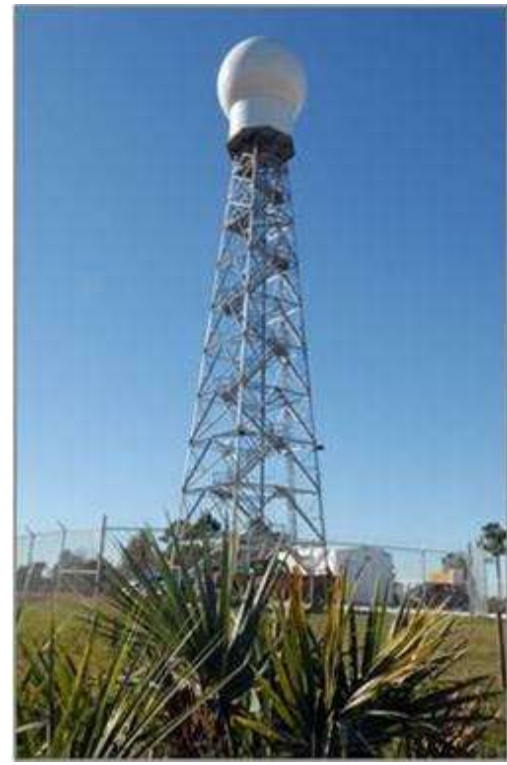

Figure 9. 45WS C-band weather radar.

\subsection{Doppler Radar Wind Profilers}

A Doppler Radar Wind Profiler (DRWP) is a radar system designed to detect the Doppler shift of clear-air turbulence in order to measure vertical profiles of wind. DRWPs work by transmitting radio pulses along two or more beams and using the Doppler shift of the returned signals from the two vectors to calculate the wind vector, and use different frequencies and different transmission powers depending on maximum height of wind required. DRWP systems are remote sensors and the maximum height probed varies with atmospheric conditions and especially latitude ${ }^{24}$. The MSFC NE group generates an extensive archive of vertically complete wind profiles using the DRWP network at the ER to 
mitigate the shortcomings of utilizing balloon-based measurements for space vehicle loads and trajectory assessments. Launching vehicles into space requires accurately characterizing the wind environment the vehicle will experience during ascent. Specific effects of the ascent winds on launch vehicles depend on the characteristics of the vehicle components and the magnitude of the wind acting on those components ${ }^{12}$. The shortfall of balloon measurements of winds are long sensing time (over 1.5 hours to measure winds from surface to $\sim 30,000 \mathrm{~m}$ ), downwind drift of the balloon (up to $280 \mathrm{~km}$ downwind or more at $\sim 30,000 \mathrm{~m}$ ), and pendulum motion of the sensor at the end of the $30 \mathrm{~m}$ string attached to the balloon.

\subsubsection{0-MHz DRWP}

Every launch passes through the atmosphere. Winds below altitudes of $18-20 \mathrm{~km}(60-65 \mathrm{kft})$ are a major concern for safety and mission assurance, guidance and steering, and aerodynamic loads. The 50-MHz DRWP is located just east of the Shuttle Landing Facility at KSC (Figure 10). The former 50-MHz DRWP consisted of an irregular octagon-shaped antenna field, which spanned 15,600 square meters (m) and consisted of coaxial-collinear elements set $1.5 \mathrm{~m}$ above the ground plane made of copper wire. These elements sent electronic pulses at $49.25 \mathrm{MHz}$ through three beams. One beam pointed vertically, and two oblique beams pointed $15^{\circ}$ off zenith at azimuths of $45^{\circ}$ and $135^{\circ}$ East from due North (Figure 11). To measure wind velocities, the 50-MHz DRWP sent radio pulses in the three beam directions sequentially and measured the return signals that were reflected by temperature and humidity fluctuations in the atmosphere. Bragg Scattering designates this process, where changes in temperature and humidity with length scales of about half of the DRWP's wavelength, ( $\sim 3 \mathrm{~m}$ for the 50-MHz DRWP), produce the return signal. A Fast Fourier Transform converted the signal in the time-domain to the frequency domain (Doppler power spectra) over 256 frequency bins at each range gate. There were 111 range gates from 2,666-18,616 m every $145 \mathrm{~m}$ and profiles were generated every three minutes ${ }^{12}$.

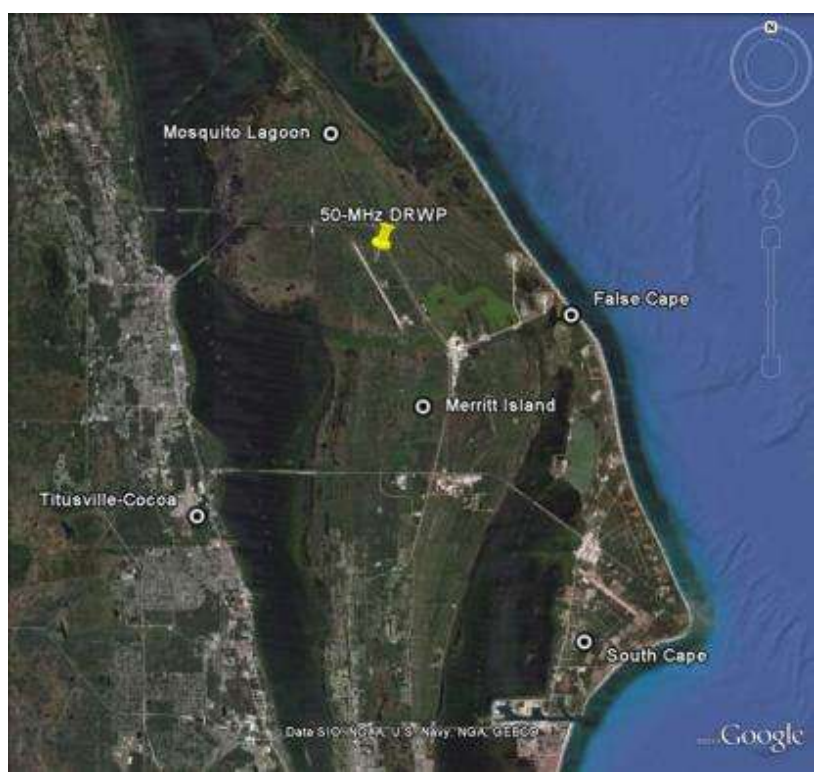

Figure 10. 50-MHz DRWP location at the ER.

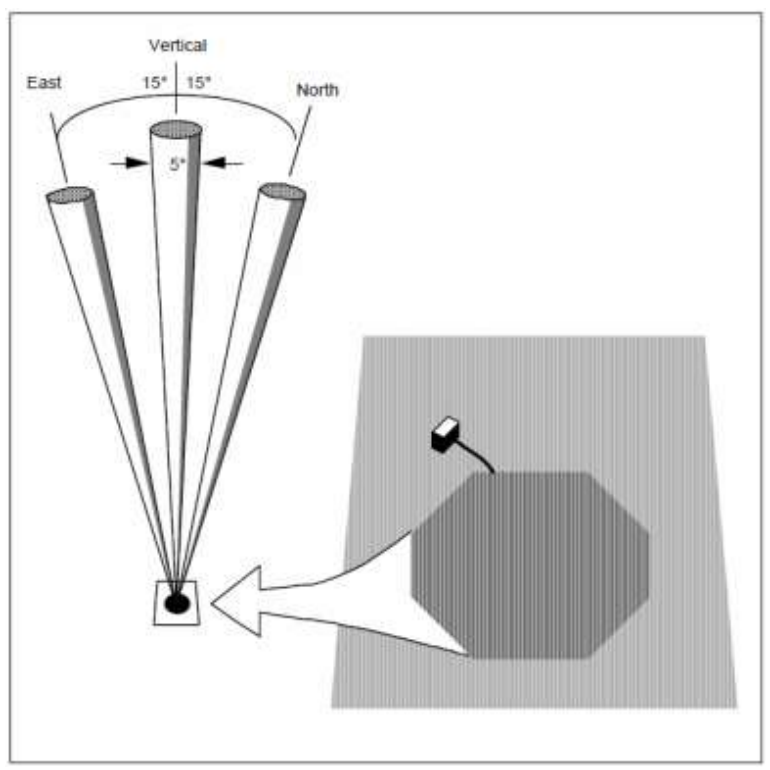

Figure 11. A schematic of the DRWP's beam configuration $^{12}$.

Currently this system is being replaced by a new 50-MHz DRWP manufactured by DeTect, Inc. The antenna of the new system will have a full beam steering (FBS) capability. (NASA will use specific pointing directions, however.) It is of a scalable design and is primarily soft-fail. The new antenna is comprised of 640 Yagi elements arranged in a thinned pattern. Each Yagi element transmits at the same power level and the antenna amplitude taper minimizes sidelobes.

This new 50-MHz DRWP, which is based on the NOAA National Profiler Network ${ }^{24}$ contains a solid state $250 \mathrm{~kW}$ transmitter, solid state programmable phase switching, and permits additional operating modes such as 4-beam and Velocity Azimuth Display (VAD) modes without modification. 


\subsubsection{5-MHz Boundary Layer DRWP Network}

A network of five 915-MHz DRWPs is arranged in a diamond-shaped pattern around the periphery of the ER (Figure 12). The 915-MHz DRWP is smaller than the 50-MHz DRWP due to its antenna structure, and thus one can use more of them in a given region. Figure 13 shows a picture of one of the 915-MHz DRWPs in the region. The network's configuration allows for each 915-MHz DRWP to potentially sample a different atmospheric boundary layer regime, especially in a dynamic environment ${ }^{12}$. This network was installed to fill the gap from the top of the wind towers to the lowest gate of the 50-MHz DRWP. Vertical profiles are generated from 120-5,000 m every $100 \mathrm{~m}$ and profiles are generated every fourteen minutes. The system's primary mission objectives are: (1) to collect wind profiles for use by the Launch Weather Officer to monitor rapidly changing weather conditions, help ensure that launch constraints are satisfied, and to provide Range Users with timely guidance during the countdown and launch pad operations; (2) to monitor rapidly changing weather conditions that could affect ground and launch operations by Range Safety and as an input to the Range Safety models used to predict the transport and diffusion of airborne contaminants released from ground level spills; and (3) to provide forecasters with a continuous description of the intermediate levels of the atmosphere for routine weather forecasting and the early detection of hazardous conditions ${ }^{25}$.

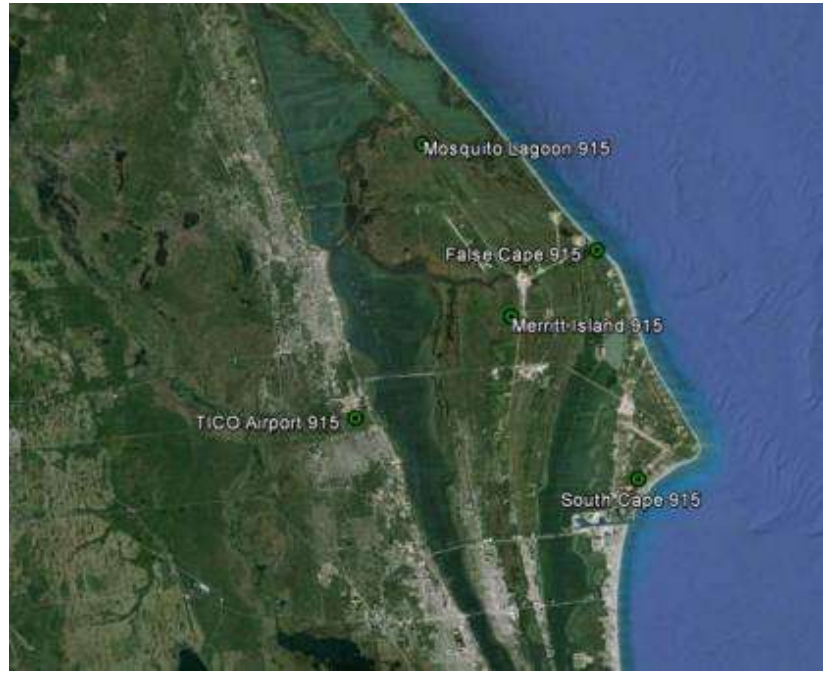

Figure 12. 915-MHz DRWP locations at the ER.

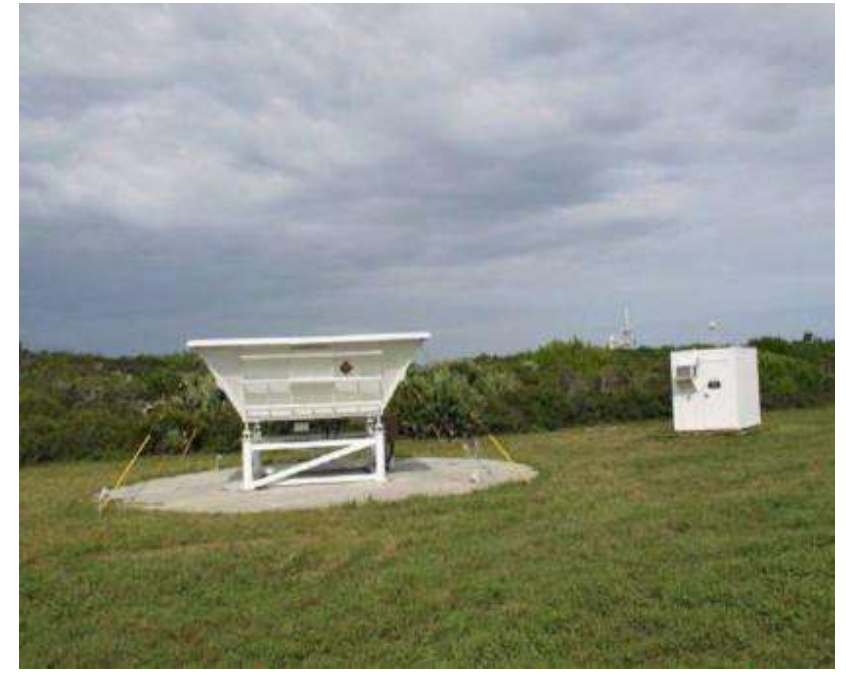

Figure 13. A 915-MHz DRWP at the ER.

\section{KA BAND OBJECT OBSERVATION AND MONITORING}

\subsection{KaBOOM}

The weather sensing technologies for processing and launching rockets will be of little use if a piece of orbital debris destroys a spacecraft in orbit or if a potentially hazardous asteroid or comet is on a collision course with the Earth. Therefore, NASA has embarked on a path to implement a high power, high resolution radar system to better track and characterize near-Earth objects (NEOs) and orbital debris. KaBOOM is a phased array of three 12 meter (m) diameter antennas at KSC. NASA is exploring the use of small diameter antennas as a phased radar array that is both scalable and extensible to achieve high power, high resolution, high reliability, simultaneous multiple direction operations, low life cycle cost, and elimination of power density restrictions. Applying this technique of coherent uplink arraying would produce a more reliable, available, scalable, extensible radar with a lower life cycle $\operatorname{cost}^{26}$.

\subsection{Potentially Hazardous Asteroids (PHA's)}

If an object is verified to be on an Earth colliding trajectory, it seems likely that this collision possibility will be known several years prior to the actual event ${ }^{27}$. With this lead time, existing technology could be used to mitigate the threat to the Earth. In the short term, the probability of an Earth impact is low, however, over longer periods of time, the probability of Earth impact is not negligible. One can view the probability of potential Earth impact events based on 
currently available observations in the Jet Propulsion Laboratory (JPL) Near-Earth Object (NEO) Program Sentry Risk Table at http://neo.jpl.nasa.gov/risk/.

Potentially Hazardous Asteroids (PHAs) are defined based on the asteroid's potential to make threatening close approaches to the Earth. Specifically, all asteroids with an Earth Minimum Orbit Intersection Distance (MOID) of 0.05 AU $(4,650,000$ miles $)$ or less, and asteroids smaller than about $150 \mathrm{~m}(500 \mathrm{ft})$ in diameter are not considered PHAs. There are currently 1487 known PHAs ${ }^{27}$.

This "potential" to make close Earth approaches does not mean a PHA will impact the Earth. It only means there is a possibility for such a threat. By monitoring these PHAs using phased array antennas such as those being demonstrated by KaBOOM, and updating their orbits, we will be able to better predict the close-approach statistics and their Earthimpact threat ${ }^{27}$.

Besides 24/7 availability for planetary protection (NEO tracking and characterization), NASA has several other uses for uplink arraying: improved detection and tracking of small $(\leq 1-10 \mathrm{~cm})$ orbital debris particles; rapidly available high power emergency uplink capability for spacecraft emergencies; radio science experiments (tomography of planetary atmospheres, general relativity tests, mass determinations, occultations, surface scattering, etc.); and beam sailing propulsion capability ${ }^{26}$.

\subsection{The Demonstration Project}

The KaBOOM demonstration consists of a phased array of three $12 \mathrm{~m}$ diameter antennas, shown in Figure 14 below. It is intended to extend prior experiments to higher frequencies, and will eventually operate near $30 \mathrm{GHz}$. Its main features are the ability (a) to produce phase-aligned signals at a distant target without external calibration, and (b) to use a downlink signal (if one is simultaneously present) to measure the effects of tropospheric turbulence along the signal paths and apply real-time corrections to the uplink signal. The effects of tropospheric turbulence increase in proportion to signal frequency, as do the effects of errors in the instrumentation ${ }^{28,29}$, making the KaBOOM demonstration particularly challenging.

In 2008, uplink arraying demonstrations were carried out by two different groups at JPL, one using two and three of the Goldstone Deep Space Network (DSN) site's $34 \mathrm{~m}$ at $7.2 \mathrm{GHz}^{30}$ and another using five $1.2 \mathrm{~m}$ antennas at $14 \mathrm{GHz}^{31}$. Both demonstrations were successful. The systems were stable and the expected change in power at the target with number of active antennas was observed. (For identical antennas and transmitters, the received power for an $\mathrm{N}$-antenna array is $\mathrm{N}^{2}$ times that of one antenna.) There was no correction for atmospheric turbulence in either case.

In 2010, NASA funded an uplink array demonstration at $8 \mathrm{GHz}$ using three $12 \mathrm{~m}$ antennas in Melbourne, FL. That experiment seemed to show that phase-aligned signals at the target can be achieved without external calibration by using internal phase-transfer electronics and correcting for measured mechanical differences among the antennas ${ }^{29,32}$. Furthermore, it was demonstrated that real-time compensation for tropospheric turbulence may be possible when there is a strong reference source in the antenna beams, such as a beacon on the target satellite. The atmosphere compensation was demonstrated not only in clear, relatively dry air, but also during Tropical Depression 16/Tropical Storm Nicole $(\text { Figure } 15)^{32}$. The present KaBOOM demonstration is using the very same $12 \mathrm{~m}$ antennas and some of the electronics that were used in the Melbourne experiment, although completely new electronics and more precise mechanical measurements will be needed at $30 \mathrm{GHz}$. 


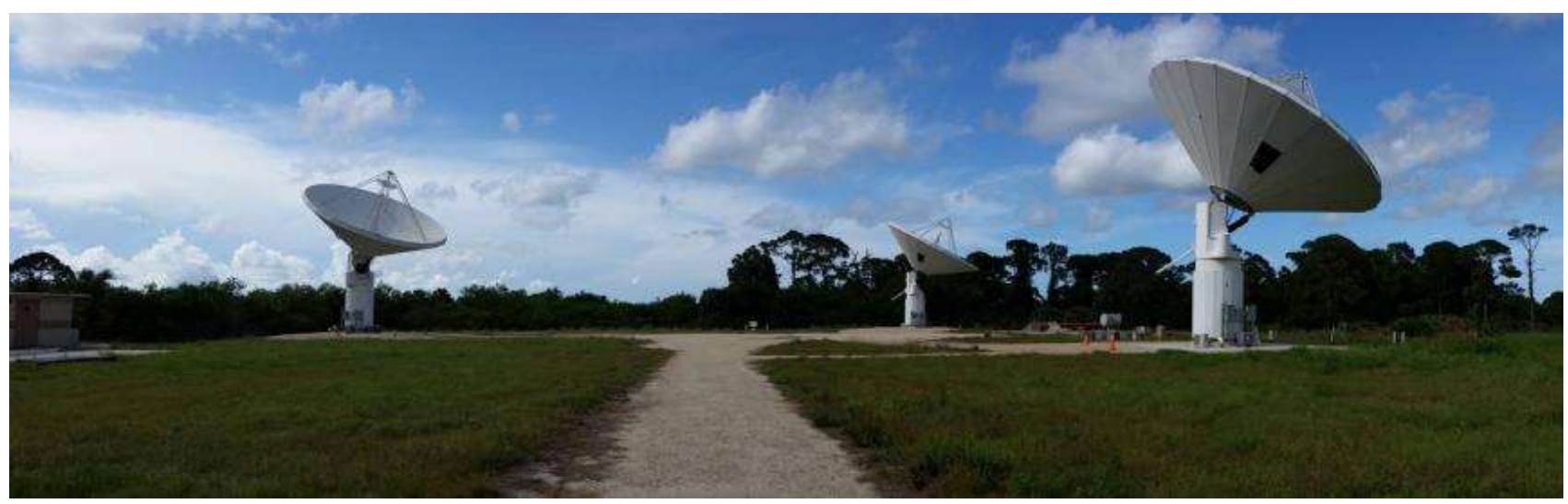

Figure 14. KaBOOM antennas at KSC.

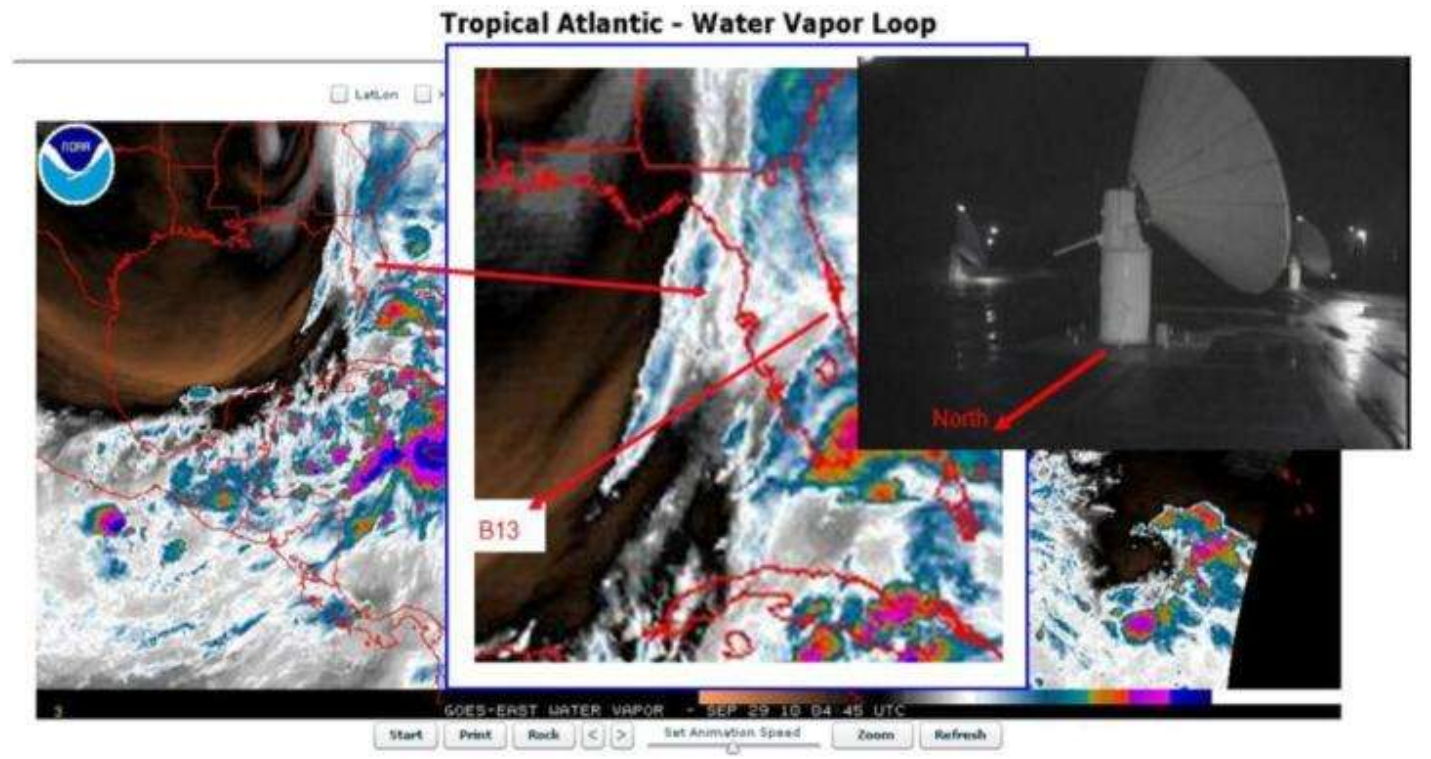

Figure 15. Tropical Atlantic water vapor loop showing environmental conditions during testing of the real-time atmospheric fluctuation compensation test in September 2010. Tropical Depression 16, September 29, 2010, 04:45 UTC. Light rain and substantial irregular water vapor content along pathway.

\section{SITE TEST INTERFEROMETERS}

\subsection{Transition to Higher Frequencies}

As NASA progresses into the 21st century, its communications network systems (e.g., Deep Space and Near Earth Networks) are expected to transition frequencies above $30 \mathrm{GHz}$. These systems will be required to provide services with a system availability of higher than $99 \%$ (versus the current $90 \%$ availability) and gigabit data rates (versus current $~$ megabit data rates). However, the atmospheric phase stability (time delay fluctuations) and attenuation of a particular site must be well characterized.

A Site Test Interferometer (STI) measures the difference in signal delay from a celestial source (typically a geostationary satellite) to two or more points on the Earth. Variations in that delay difference are primarily due to turbulence in the troposphere, which creates a difference in the mean refractive indices along the paths ${ }^{33}$. 
An STI constructed by the JPL and based on a design provided by the Harvard Smithsonian Center for Astrophysics (CfA) has been installed at KSC. Nearly identical instruments have been deployed by JPL at five additional sites around the world, and other STIs have been in operation at radio observatories for many years. The KSC STI uses three small $(0.8 \mathrm{~m})$ antennas in a triangular configuration with spacings of 135 to $289 \mathrm{~m}$ to receive and process signals from a commercial geostationary satellite (NIMIQ 5, azimuth $163.8^{\circ}$ and elevation $55.6^{\circ}$ ). The observed turbulence varies with weather and season, but its effect over $\sim 200 \mathrm{~m}$ distance scales is not measurable by ordinary meteorological instruments, hence the need for a specialized instrument. While the STI is designed to provide a long-term statistical characterization of the site, it will also help KaBOOM to determine how much its signals are being disrupted by the atmosphere in nearreal-time, and thus provide a measure of how well KaBOOM's atmosphere compensation process is working ${ }^{34}$.

\subsection{Operational Sites}

Two STIs have been operating at the NASA DSN site in Goldstone, California for several years ${ }^{33}$. These instruments have two and three antennas, respectively, with element separations of $\sim 200 \mathrm{~m}$. Three-element STIs have also been installed at the Canberra and Madrid DSN sites. The antennas continuously observe signals emitted by geostationary satellites, and the phase difference of the received signals is measured. During post-processing, long period trends due to satellite motion and instrumental drift are removed. Fluctuations in the resulting phase delay residuals are dominated by the troposphere on timescales ranging from $<<1 \mathrm{~s}$ to several hundred seconds ${ }^{33}$.

Although an STI and a nearby communication array or radio telescope are expected to see the same short- and long term statistical delay fluctuations, the instantaneous delay measured by the STI is generally not useful for correcting delay errors in the array because their targets are in different directions and their signals pass through different parts of the turbulent distribution. However, the statistics acquired over long periods are useful for characterizing the site.

The statistics vary among sites due to climate and altitude and at any one site diurnally, seasonally, and with passage of weather systems. The long-term statistics can be used to determine the suitability of a site for hosting an array, or they can be used in communication link budgets of current or proposed missions using an array at the site. Short-term (intraday) statistics can be used to assist in scheduling communication links so that the best conditions are used for links with small margins, and conversely ${ }^{33}$.

We intend to operate the STI several years in order to obtain sufficient data for reliable statistical characterization of our $\mathrm{KaBOOM}$ site. The KaBOOM/STI location is shown in Figure 16 and a picture of one of the STI elements is shown in Figure 17. Figure 18 displays the zenith delay root mean square (RMS) for all three KSC STI baselines for the month of September 2013. One can clearly see a diurnal variation, where the delay RMS peaks within a few hours of local noon. Figure 19 displays the cumulative distribution of the delay RMS for several months since the instrument started operations in August 2013. One can clearly see a seasonal trend where the zenith delay RMS is higher during summer than during the winter for a given $\mathrm{CD}$ value. 


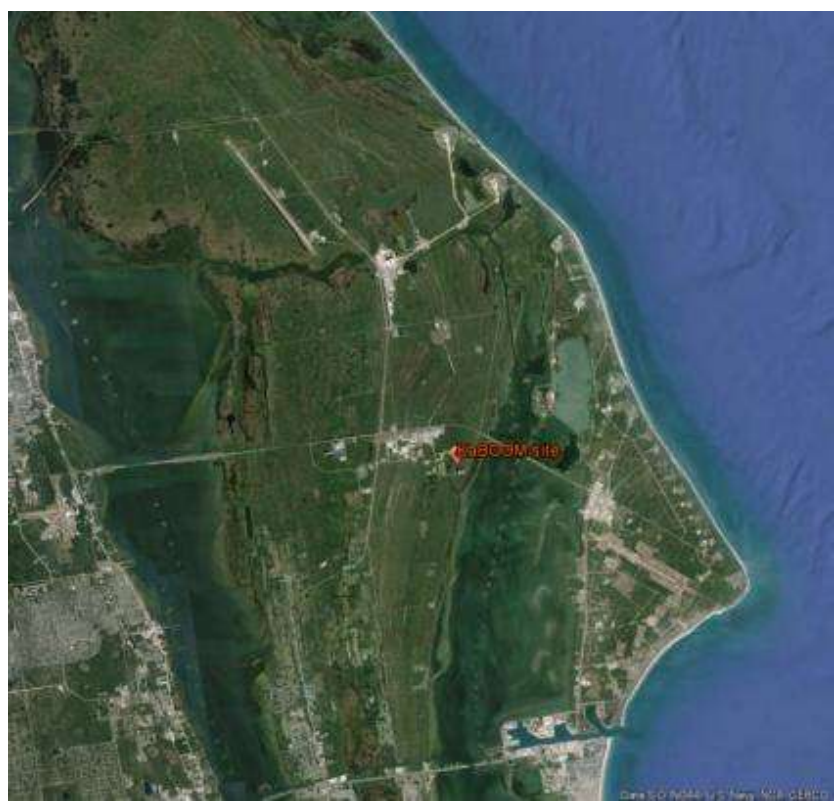

Figure 16. Location of the KaBOOM antennas and STI instrument at KSC.

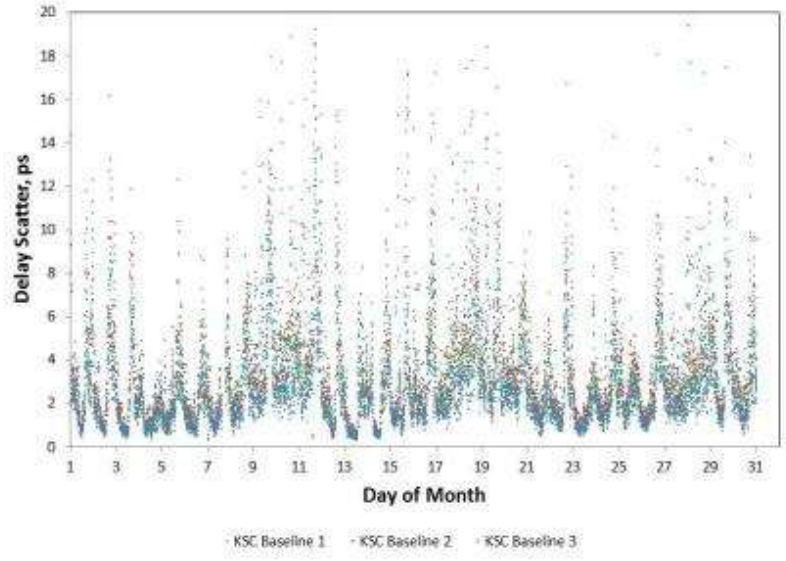

Figure 18. Delay RMS in 600-s blocks referenced to zenith for the KSC STI (all three baselines).

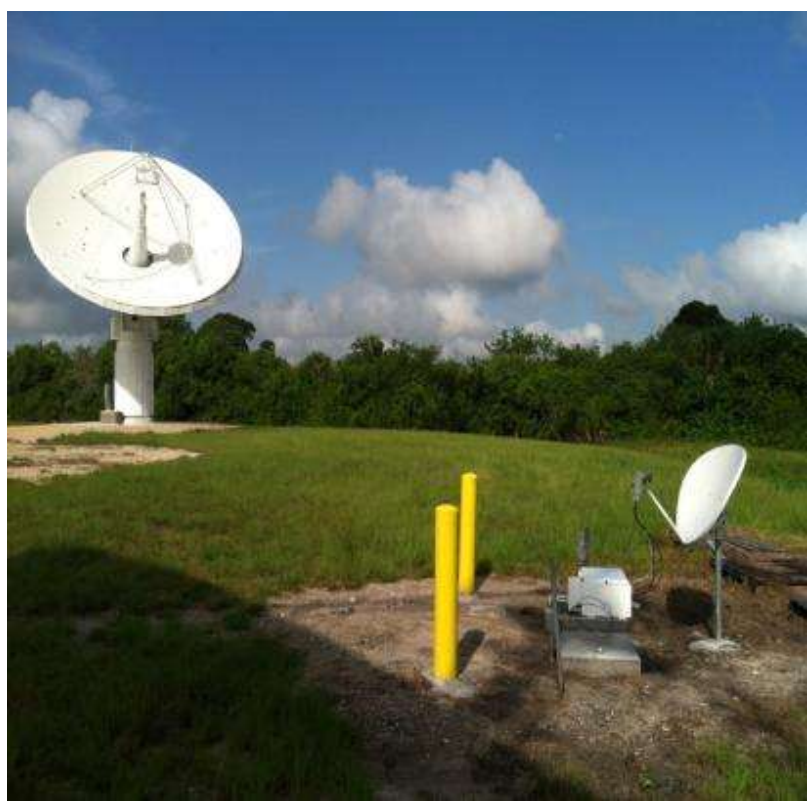

Figure 17. Foreground: one of three small antennas that make up the STI instrument. Background: one of the larger antennas of the $\mathrm{KaBOOM}$ demonstration.

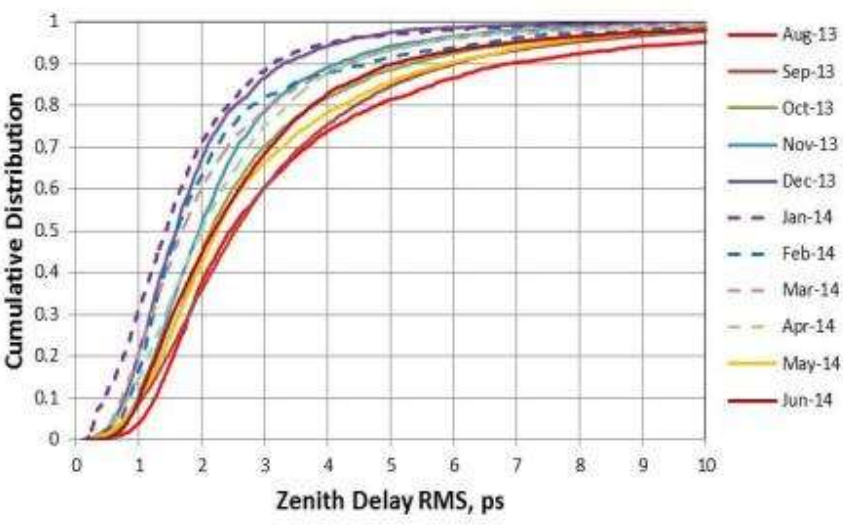

Figure 19. Monthly cumulative distribution curves of zenith delay RMS for the KSC STI (warmer months shown in reddish curves, winter months in bluish/purplish curves.

\section{CONCLUSION}

Remote sensing in meteorology is normally thought of as being done from satellites. However, ground-based remote sensing is also important in operational meteorology. As is described, ground-based remote sensing is critical to the success of America's space program at NASA's Kennedy Space Center and Cape Canaveral Air Force Station in Florida. In addition, the Ka Band Object Observation and Monitoring project, which is a unique application of remote sensing being developed to improve capability for tracking space debris and near Earth asteroids will become more important as future satellites are deployed and greater use is made of Low Earth Orbit (LEO). Site Test Interferometers, which will allow for scheduling observations to minimize atmospheric degradation on the project's operations is an example of the emerging ground based technology that will support and enhance future remote sensing capabilities. 


\section{REFERENCES}

[1] Boyd, B. F., Madura, J. T., and Adams, M. E., "Meteorological support to the United States Air Force and NASA at the Eastern Range and Kennedy Space Center," Paper 93-0753, AIAA $31^{\text {st }}$ Aerospace Sciences Meeting and Exhibit, (January 1993).

[2] Hazen, D. S., Roeder, W. P., Boyd, B. F., Lorens, J. B., and Wilde, T. L., "Weather impact on launch operations at the Eastern Range and Kennedy Space Center," Preprints, Sixth Conf. on Aviation Weather Systems, Amer. Meteor. Soc., pp. 270-275. (1995).

[3] Krider, E .P., Koons, H. C., Walterscheid, R. L., Rust, W. D., and Willett, J. C., " Natural and triggered lightning launch commit criteria (LCC), " Aerospace Report No. TR-99(1413)-1, 15 January 1999.

[4] Krider, E. P., Christian, H. J., Dye, J. E., Koons, H. C., Madura, J. T., Merceret, F. J., Rust, D. L., Walterscheid, R. L., and Willett, J. C., " Natural and triggered lightning launch commit criteria (LCC)," Conference on Aviation, Range and Aerospace Meteorology, (2006).

[5] McNamara, T. M., Roeder, W. P., and Merceret, F. J., "The 2009 update to the lightning launch commit criteria, " 14th Conference on Aviation, Range, and Aerospace Meteorology, (2010).

[6] Roeder, W. P., Hajek, D. L., Flinn, F. C., Maul, G. A., and Fitzpatrick, M. E., "Meteorological and oceanic instrumentation at Spaceport Florida - opportunities for coastal research," 5th Conference on Coastal Atmospheric and Oceanic Prediction and Processes, (2003).

[7] Boyd, B. F., Roeder, W. P., Lorens, J. B., Hazen, D. S., and Weems, J., "Weather Support to Pre-launch operations at the Eastern Range and Kennedy Space Center," Preprints 6th Conference on Aviation Weather Systems, pp. 135140, (1995).

[8] Walterscheid, R. L., Willett, J. C., Krider, E. P., Gelinas, L. J., Law, G. W., Peng, G. S., Seibold, R. W., Simmons, F. S. and Zittel, P. F., "Triggered lightning risk assessment for reusable launch vehicles at four regional spaceports, " Aerospace Report No. ATR-2010(5387)-1, (30 April 2010).

[9] Willett, J.C., Merceret, F. J., Krider, E. P., Dye, J. E., O'Brien, T. P., Rust, W. D., Walterscheid, R. L., Madura, J. T., and Christian, H. J., "Rationales for the Lightning Flight Commit Criteria," NASA/TM-2010-216291, 236 pp. (2010).

[10]Roeder, W. P., "Lightning has fallen to third leading source of U.S. storm deaths," 2012 Annual Meeting of the National Weather Association, (2012).

[11]Barbré, R.E., "Characteristics of the Spliced KSC Doppler Radar Wind Profiler Database". Jacobs ESSSA Group Analysis Report. ESSSA-FY13-1935.

[12] Boyd, B. F., Harms, D. E., Fitzpatrick, M. E., Stout, R. P., Rosati, P. N., Berlinrut, D. D., Parks, C. R., and Overbeck, K. B., "Weather Support To Range Safety," Joint Army Navy NASA Air Force Safety \& Environmental Protection Subcommittee, CPIA Pub. 687, Vol. I, pp. 59-69. (1999).

[13] Boyd, B. F., Harms, D. E., Rosati, P. N., Parks, C. R., and Overbeck, K. B., "Weather Support To Range Safety For Forecasting Atmospheric Sonic Propagation," 9th Conference on Aviation, Range, and Aerospace Meteorology, pp. 432-437. (2000).

[14]Harms, D.E., Boyd, B. F., Flinn, F. C., McNamara, T. M., Madura, J. T., Wilfong, T. L., and Conant, P. R., "Weather system upgrades to support space launch at the Eastern Range and Kennedy Space Center." 12th Symposium on Meteorological Observations and Instrumentation, (2003).

[15] Huffines, G. R. and Orville, R. E., "Lightning ground flash density and thunderstorm duration in the continental United States: 1989-96," Journal of Applied Meteorology, 38, 1013-1019 (1999).

[16] Roeder, W.P. and Saul, J. M., 2012. "Four Dimensional Lightning Surveillance System: Status and Plans," 22nd International Lightning Detection Conference, (2012).

[17] Roeder, W. P., "The Four Dimensional Lightning Surveillance System," 21st International Lightning Detection Conference, (2010).

[18] Cummins, K. L., Cramer, J. A., Biagi, C. J., Krider, E. P., Jerauld, J., Uman, M. A., Rakov, V. A., "The U.S. National Lightning Detection Network: Post upgrade status, " 2nd conference on Meteorological Applications of Lightning Data, (2006).

[19] Roeder, W.P., McNamara, T. M., Boyd, B. F., and Merceret, F. J., "The new weather radar for America's space program in Florida: an overview," 34th Conference on Radar Meteorology, (2009).

[20] Roeder, W.P., T.M. McNamara, T. M., B.F. Boyd, B. F., J.W. Weems, J. W., and S.B. Cocks, S. B., "Unique uses of weather radar for space launch". 32nd Conference on Radar Meteorology, (2005). 
[21] Thurmond, K. R., "Operational cloud-to-ground lightning forecasting utilizing S band dual-polarization radar, " M.S. thesis, Air Force Institute of Technology, Wright-Patterson Air Force Base, OH, AFIT-ENP-14-M-36, 72 pp. (2014).

[22] Woodard, C. J., Carey, L. D., Petersen, W. A., and Roeder, W. P., "Operational utility of dual-polarization variables in lightning initiation forecasting, " Electronic Journal of Operational Meteorology, 13 (6), 79-102, (2012)

[23] Ryzhkov, A. V., Schuur, T. J., Burgess, D. W., and Zrnic, D. S., 2005: Polarimetric tornado detection, Journal of Applied Meteorology, 44, 557-570 (2005).

[24] McLaughlin, S. and Wilfong, T. L., "NASA 49.25 MHz and NWS 449 MHz Radar Wind Profilers," Presentation given at the March 19-20, 2014 Day of Launch Working Group (DOLWG) meeting, Kennedy Space Center, FL, (March 2014).

[25] Eastern Range Instrumentation Handbook, "Eastern Range Instrumentation Handbook," (CDRL B312), Systems Engineering and Analysis, Computer Sciences Raytheon, Patrick AFB, FL 32925, Contract FA2521-07-C-0011, (2012).

[26] Geldzahler, B.J., "Coherent uplink arraying techniques for next generation orbital debris, near earth object, and space situational awareness radar systems," Proc. SPIE 8382, Active and Passive Signatures III, (2012).

[27] Yeomans, D., "Near Earth Object Program," NASA Jet Propulsion Laboratory, 7 July 2014, $<$ http://neo.jpl.nasa.gov/neo/>/(14 July 2014).

[28] Shambayati, S., Border, J. S., Morabito, D. D., and Mendoza, R., "MRO Ka-band demonstration: cruise phase lessons learned,". IEEE Aerospace Conference, pp.1-17. (2007).

[29] Gelzahler, B. J., Seibert, M. A., Miller, M. J., Vilnrotter, V., and Tsao, P., "KaBOOM - Band Objects: Observation and Monitoring," Advanced Maui Space Surveillance and Optical Technologies Conference, (2012).

[30] Vilnrotter, V., Lee, D., Cornish, T., Tsao, P., Paal, L., and Jamnejad, V., "Uplink Array Concept Demonstartion with the EPOXI Spacecraft," IEEE Aerospace Conference, (2009).

[31] D'Addario, L., R. Proctor, J. Trinh, E. Sigman, and C. Yamamoto, "Uplink Array Demonstration With GroundBased Calibration," Interplanetary Network Progress Report, Vol 42-176. http://ipnpr.jpl.nasa.gov. (2009).

[32] Martin, P., Minear, K., Geldzahler, B., and Soloff, J., "Large Reflector Uplink Arraying," SpaceOps 2010 Conference, (2010).

[33] Morabito, D.D., D'Addario, L. R., Acosta, R. J., and Nessel, J. A., "Tropospheric delay statistics measurement by two site test interferometers at Goldstone, California," Radio Science 48, 1-10 (2013).

[34] Morgan, J. G. and Morabito, D. D., "Implementation of the site test interferometer (STI) at KSC", KaBOOM Memo No. 7, pp. 1-11, (December 2013). 


\section{APPENDIX A - LIST OF ACRONYMS}

\begin{tabular}{|c|c|c|c|}
\hline $3-\mathrm{D}$ & three dimensional & $\mathrm{LCC}$ & Launch Commit Criteria \\
\hline $45 \mathrm{WS}$ & 45th Weather Squadron & LDAR & Lightning Detection and Ranging \\
\hline \multirow{2}{*}{ 4DLSS } & Four Dimensional Lightning & LO & local oscillator \\
\hline & Surveillance System & LPLWS & Launch Pad Lightning Warning System \\
\hline AFB & Air Force Base & $\mathrm{m}$ & meter \\
\hline CCAFS & Cape Canaveral Air Force Station & MERLiN & Mesoscale Eastern Range Lightning \\
\hline CfA & Center for Astrophysics & & Network \\
\hline \multirow[t]{2}{*}{ CGLSS } & Cloud-to-Ground Lightning & $\mathrm{MHz}$ & megahertz \\
\hline & Surveillance System & MSFC & Marshall Space Flight Center \\
\hline \multirow{2}{*}{$\begin{array}{l}\mathrm{cm} \\
\text { DoD }\end{array}$} & centimeter & NASA & National Aeronautics and \\
\hline & Department of Defense & & Administration \\
\hline DRWP & Doppler Radar Wind Profiler & $\mathrm{NE}$ & Natural Environments \\
\hline DSN & Deep Space Network & NEO & Near-Earth Object \\
\hline \multirow{2}{*}{$\begin{array}{l}\text { ER } \\
\text { FAA }\end{array}$} & Eastern Range & NEXRAD & Next Generation Weather Radar \\
\hline & Federal Aviation Administration & NLDN & National Lightning Detection Network \\
\hline $\mathrm{GHz}$ & gigahertz & NM & nautical mile \\
\hline HQ & Headquarters & NWS & National Weather Service \\
\hline IF & intermediate frequency & ps & picosecond \\
\hline JPL & Jet Propulsion Laboratory & RMS & root mean square \\
\hline \multirow{2}{*}{\multicolumn{2}{|c|}{$\begin{array}{c}\text { KaBOOM Ka band Objects Observation and } \\
\text { Monitoring }\end{array}$}} & $\mathrm{s}$ & second \\
\hline & & STI & Site Test Interferometer \\
\hline kft & kilofeet & U.S. & United States \\
\hline $\mathrm{km}$ & kilometer & USAF & United States Air Force \\
\hline $\mathrm{KSC}$ & Kennedy Space Center & VAD & Velocity Azimuth Display \\
\hline $\mathrm{kV} / \mathrm{m}$ & kilovolts per meter & VHF & very high frequency \\
\hline $\mathrm{kW}$ & kilowatt & WSR-88D & Weather Surveillance Radar 1988 \\
\hline LEO & Low Earth Orbit & & Doppler \\
\hline
\end{tabular}

xxiv 